\title{
PREVALENCE OF LIGAMENTOUS INJURY ASSOCIATED WITH EXTRA ARTICULAR DISTAL RADIUS FRACTURE
}

\author{
By
}

\section{Ahmed Abdallah Mohamed, Aly Mohamed El-Geoushy and Galal Mohamed Mansour}

\author{
Department of Orthopedic Surgery, Faculty of Medicine, Al Azhar University \\ Corresponding Author: Ahmed Abdallah Mohamed, \\ E-mail: dr.mansy3890@gmail.com
}

\begin{abstract}
Background: The radius is the most commonly broken bone in the arm. Distal radius fractures are very common and are commonly associated with ligament injuries and chondral damage.

Objective: To report the incidence of ligaments and cartilage lesions associated with extra-articular distal radius fracture.

Patients and methods: Fifty consecutive patients with extra-articular distal radius fractures, who attended at Al-Azhar University Hospital during the study period, were included in the study. $42.0 \%$ of the patients were males, $58.0 \%$ of them were females, and their mean age was $45.5 \pm 5.24$ years.

Results: The affected wrist was the right wrist in $56 \%$ of cases and on plain radiographs. $46 \%$ of cases had A2 fractures, and 54\% of them had A3 fractures. Ligament and cartilage lesions were found in $88 \%$ of cases. No significant statistical association was found between the intracarpal soft tissue injury and the different types of fractures.

Conclusion: Using arthroscopy is recommended in distal radius fractures for verification of the degree of associated injuries and larger studies are needed to confirm our results.
\end{abstract}

Keywords: Extra-articular radius fractures, Ligamentous injuries, Intracarpal soft tissue injury.

\section{INTRODUCTION}

One of the most common distal radius fractures is Colles fracture, in which the broken fragment of the radius tilts upward. The distal radius may also break as intra-articular fracture, extra-articular fracture, open fracture or comminuted fracture (Caldwell et al., 2019).

Distal radial fractures most frequently occur as a result of fall on the outstretched hand injuries. In the elderly, they are often the result of low-energy falls from a standing or seated position (Meena et al., 2014). The initial management of distal radius fractures includes neurovascular and soft-tissue assessment, reduction and immobilization. Standard antero-posterior and lateral radiographs are sufficient in the majority of cases and advanced imaging might be used infrequently. Surgery might be needed for management of intra-articular distal radius fractures (Smith, 2018). Wrist arthroscopy is a valuable tool in the management of distal radius fractures as it can help in 
restoration of the articular surface as well as in identification of associated soft tissue injuries (Shkolnikova and Harvey, 2018).

Distal radius fractures are commonly associated with ligament injuries and chondral damage as well (Swart and Tang, 2017). Ligament and intra-articular cartilaginous injuries associated with the fractures might explain poor functional results following treatment of these fractures and might be associated with poor prognosis (Araf and Mattar, 2014).

The aim of this prospective study was to report the incidence of ligaments and cartilage lesions associated with extra-articular distal radius fracture.

\section{PATIENTS AND METHODS}

This study was conducted on 50 consecutive patients with extra-articular distal radius fractures, who attended at the emergency department or the orthopedics outpatient clinic at Al-Azhar University Hospital during the period April-October 2019. Only patients aged 18-60 years, with closed extra-articular fractures were included. Patients with open fracture, multiple trauma, bilateral distal radius fracture or pathological fracture were excluded.

\section{Every patients was subjected to:}

History taking: full history was taken from patients including: age, gender.

Physical examination including general examination (to detect any associated injuries) and local examination of the injured radius (giving attention to skin condition and neurovascular assessment).

Radiological evaluation with standard antero-posterior (AP) and lateral X-rays.

\section{Management:}

A. Routine pre-operative evaluation including complete blood picture, kidney and liver function tests, random blood sugar, bleeding and coagulation profiles.

B. Intra-operative management:

- Position: The patient was seated in the supine position with the affected hand suspended with $5 \mathrm{Kg}$. of counter traction.

- Surgical technique: Under general anesthesia, the patient's hand was suspended with $5 \mathrm{~kg}$ of counter traction. The arm was exsanguinated and an upper arm tourniquet was inflated to $250 \mathrm{mmHg}$. Saline was then infused to distend the joint capsule to the portal level $(3-4)$, which is located by palpating the radius carpal joint between the third and fourth extensor compartments. After capsular distension, a small incision was made in this site with scalpel blade number 11. A rhombus trocar with its shirt was introduced into the portal and after removing the trocar, the optic was introduced into the shirt. Then a 40x10 needle was inserted into the $6 \mathrm{U}$ portal (ulnar to the extensor carpi ulnaris) to provide an exit for the saline (outflow). The following portals were used for visualization and instrumentation: 4,5 and $6 \mathrm{R}$ (radiocarpal) and mediocarpals (radial and ulnar). During arthroscopy, all associated cartilage and ligament injuries were diagnosed, classified and treated. After arthroscopic inspection, the procedures for reconstruction of the 
distal radius fracture (osteosynthesis) were started, with the aid of arthroscopy and image intensifier. Fractures were managed in either closed or open way, using internal fixation with Kirschner wires, screws, with and without "T" plate lock.

C. Post-operative management: Patients received post-operative antibiotics and analgesics. AP radiographs were obtained postoperatively and at each follow-up visit to determine fracture alignment.

Ethical approval: The study protocol received approval from the Institutional Review Board- Al-Azhar Faculty of Medicine. Administrative approval and official permissions were obtained prior to data collection. Written informed consents were obtained from patients prior to surgery with a verbal consent to be included in the study following guarantee of data confidentiality to them.

\section{Statistical analysis:}

Data were collected, revised, coded, tabulated and analyzed using the Statistical Package for the Social Science (IBM SPSS) version 20. Quantitative data were presented as mean, standard deviations and ranges. Meanwhile, qualitative variables were presented as number and percentages. The appropriate test of significance was conducted Chisquare test was used in the comparison between two groups with qualitative data and Fisher exact test was used instead of the Chi-square test when the expected count in any cell found less than 5 . The confidence interval was set to $95 \%$ and the margin of error accepted was set to $5 \%$. So, the p-value was considered significant at the level of $<0.05$.

\section{RESULTS}

As regards the characteristics of patients, $42.0 \%$ of patients were males, $58.0 \%$ of them were females and their ages ranged from 20 to 60 years with a mean age of $45.5 \pm 5.24$ years. The affected wrist was the right wrist in $56 \%$ of cases and was the left wrist in $44 \%$ of cases. On plain radiographs, $46 \%$ of cases had A2 fractures and 54\% of cases had A3 fractures. Ligament and cartilage lesions were found in $88 \%$ of cases with triangular fibrocartilage complex injury, lunotriquetral interosseous ligament injury and scapholunate interosseous ligament injury in $56 \%, 20 \%$ and $12 \%$ of the cases respectively (Table 1). 
Table (1): Demographic, characteristics of fractures and ligament and cartilage lesions in the study group

\begin{tabular}{|c|c|c|c|}
\hline & & No & $\%$ \\
\hline \multirow{2}{*}{ Gender } & Male & 21 & $42.0 \%$ \\
\hline & Female & 29 & $58.0 \%$ \\
\hline \multirow{2}{*}{ Age (years) } & Mean \pm SD & \multicolumn{2}{|c|}{$45.5 \pm 5.24$} \\
\hline & Range & \multicolumn{2}{|c|}{$20-60$} \\
\hline \multirow{2}{*}{ Affected wrist } & Right & 28 & $56.0 \%$ \\
\hline & Left & 22 & $44.0 \%$ \\
\hline \multirow{2}{*}{ AO classification } & A2 fracture & 23 & $46 \%$ \\
\hline & A3 fracture & 27 & $54 \%$ \\
\hline \multicolumn{2}{|c|}{ Triangular fibrocartilage complex injury } & 28 & $56.0 \%$ \\
\hline \multicolumn{2}{|c|}{ Lunotriquetral interosseous ligament injury } & 10 & $20.0 \%$ \\
\hline \multicolumn{2}{|c|}{ Scapholunate interosseous ligament injury } & 6 & $12.0 \%$ \\
\hline
\end{tabular}

No significant statistical association was found between the intracarpal soft tissue injury and the different types of fractures (Table 2).

Table (2): Intracarpal soft tissue injury with different types of fractures

\begin{tabular}{|c|c|c|c|c|c|c|}
\hline \multirow{2}{*}{ AO classification } & \multicolumn{2}{|c|}{ TFCC injury } & \multicolumn{2}{c|}{ LTIL injury } & \multicolumn{2}{c|}{ SLIL injury } \\
\cline { 2 - 7 } & No & $\%$ & No & \% & No & \% \\
\hline A2 fracture (No.=23) & 10 & $43 \%$ & 3 & $13 \%$ & 2 & $9 \%$ \\
\hline A3 fracture (No.=27) & 18 & $67 \%$ & 7 & $26 \%$ & 4 & $15 \%$ \\
\hline P value & \multicolumn{2}{|c|}{$>0.05$} & \multicolumn{2}{|c|}{$>0.05$} & \multicolumn{2}{c|}{$>0.05$} \\
\hline
\end{tabular}

TFCC, Triangular fibrocartilage complex; LTIL, Lunotriquetral interosseous ligament; SLIL, Scapholunate interosseous ligament.

\section{DISCUSSION}

The present study revealed that $42.0 \%$ of distal radius fracture patients were males and $58.0 \%$ of them were females and that their ages ranged from 20 to 60 years with a mean age of $45.5 \pm 5.24$ years. These findings, concerning age, differ from those obtained in the study performed on 30 patients with unilateral intra-articular closed fracture of the distal radius with surgical treatment indication as it was found that the mean age of patients was $40.30 \pm 8.14$ years (Araf and Mattar, 2014). This difference might be explained by the different inclusion criteria as regards age as they included patients aged 20-50 years old meanwhile the current study included patients aged
18-60 years old. On the other hand, and as regards the higher percentage of females being affected, this finding can be explained by the fact that women are known to have a significantly greater risk of this injury than men in this age group (Nellans et al., 2012). Similar finding, of fracture distal radius being more common among women, was reported in a study that was performed in southern Sweden on 335 persons with acute distal radius fracture (Brogren et al., 2010).

The present study revealed that the affected wrist was the right wrist in $56 \%$ of distal radius fracture patients and was the left wrist in $44 \%$ of them. Meanwhile, $50 \%$ affection of the right wrist was reported in a previous study (Araf and 
Mattar, 2014). This difference might be explained by the different age groups of patients included with different mechanisms and severity of trauma. The present study revealed also that $46 \%$ of distal radius fracture patients had A2 fractures and $54 \%$ of them had A3 fractures on plain radiographs. This finding comes in line with was published in 2010 as it was reported that type-A fracture was the most common among patients with distal radius fractures (Brogren et al., 2010).

Meanwhile, different frequencies of AO classification were reported with the highest percentage of patients (13.3\%) having B3.2 fractures and another 13.3\% of them having C2.3 fractures (Araf and Mattar, 2014). This difference might be explained by the different age groups of patients included with different mechanisms of trauma.

Regards the associated ligament and cartilage lesions, the current study revealed that the commonest associated injury was the triangular fibrocartilage complex injury that was found in $56 \%$ of distal radius fracture patients followed by lunotriquetral interosseous ligament injury and scapholunate interosseous ligament injury that were found in $20 \%$ and $12 \%$ of them respectively. Similar to our experience, the triangular fibrocartilage complex injury was found to be the commonest associated injury in a number of previous studies (Brogren et al., 2010, Araf \& Mattar, 2014 and Swart \& Tang, 2014).

The present study revealed that there was no significant statistical association between the intracarpal soft tissue injury and the different types of fractures. This finding comes in line with that published in 2013 as no significant difference was found between extra-articular and intraarticular fractures with respect to the frequencies of ligamentous injury (Ogawa et al., 2013). On the other hand, this finding differs from what was reported in another study as it was found that in groups with ligament injury there is a statistically significant difference regarding AO/ASIF classification (Araf and Mattar, 2014). This difference might be explained by the different classification of fractures included as they found that ligament injury was more common in classes $\mathrm{C} 1, \mathrm{C} 2$ and $\mathrm{C} 3$ which were not present in our study.

Results of this study were limited by the small sample size which did not provide much statistical power for the results and a larger dataset is needed to confirm our findings. Some other factors such as mechanism and severity of trauma, duration to and mode of transport to hospital, fracture position at presentation, bone density as well as severity of ligament injury were not included in this study.

\section{CONCLUSION}

Our results confirm the high incidence of associated injuries, especially those of the triangular fibrocartilage complex, in patients with distal radius fractures.

\section{REFERENCES}

1. Araf $M$ and Mattar R. (2014): Arthroscopic study of injuries in articular fractures of distal radius extremity. Acta Ortop Bras., 22(3):144-50.

\section{Brogren E, Petranek $M$ and Atroshi} I. (2010): Incidence and characteristics 
of distal radius fractures in a southern Swedish region. BMC Musculoskelet Disord., 8:48-52.

3. Caldwell RA, Shorten PL and Morrell NT. (2019): Common Upper Extremity Fracture Eponyms: A Look Into What They Really Mean. J Hand Surg Am., 44(4):331-334.

4. Meena S, Sharma P, Sambharia AK and Dawar A. (2014): Fractures of distal radius: An overview. J Family Med Prim Care, 3(4):325-32.

5. Nellans KW, Kowalski E and Chung KC. (2012): The epidemiology of distal radius fractures. Hand Clin., 28(2):113-25.

6. Ogawa T, Tanaka T, Yanai T, Kumagai $H$ and Ochiai N. (2013): Analysis of soft tissue injuries associated with distal radius fractures.
BMC Sports Science, Medicine and Rehabilitation, 5:19-23.

7. Shkolnikova J and Harvey J. (2018): Wrist arthroscopy in the management of distal radius fractures. Annals of Joint, 3: 1-13.

8. Smith D. (2018): Treating intraarticular distal radius fractures. BCMJ., 60(1):17-21.

9. Swart E and Tang P. (2017): The effect of ligament injuries on outcomes of operatively treated distal radius fractures. Am J Orthop., 46(1):41-46. 


\section{إنتشار إصابه الاربطه المصاحب لكسور أسفل عظمة الكعبرة أحمد عبدالله محمد عبدالله، علي محمد الجيوشي، جلال محمد منصور الهور}

\section{قسم جراحة العظام، كلية الطب، جامعة الأزهر}

E-mail: dr.mansy3890@gmail.com

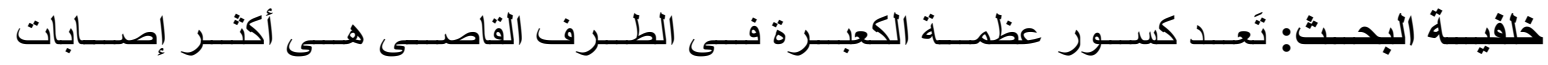

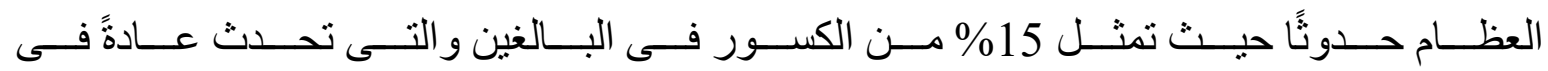

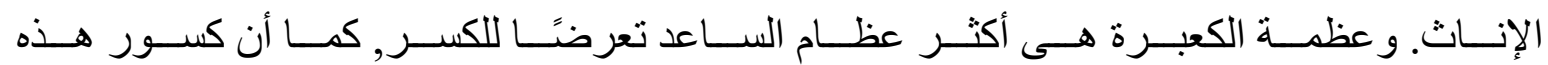

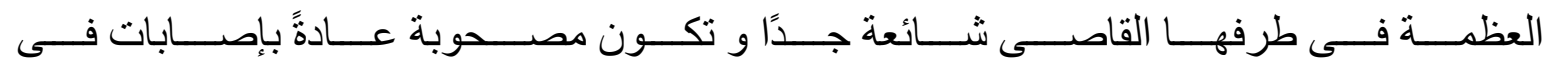

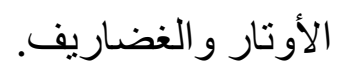

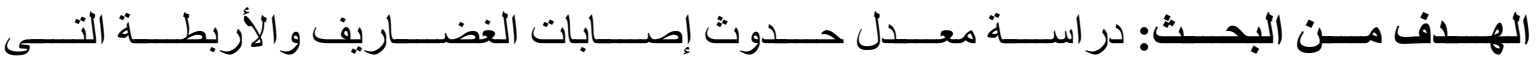
تصاحب كسور عظمة الكعبرة فى الطرف القاصى.

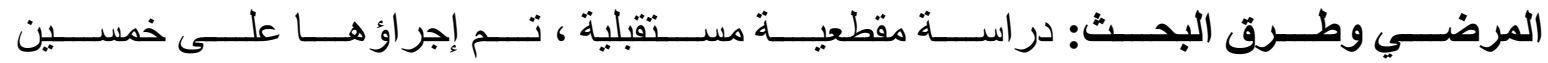

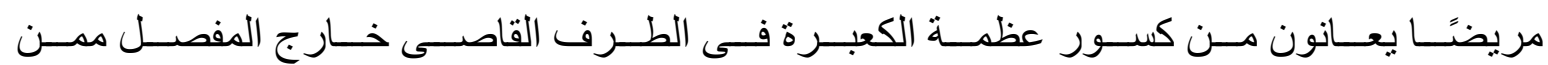

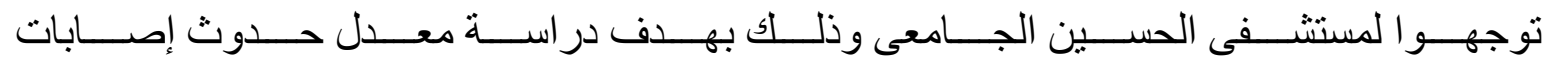

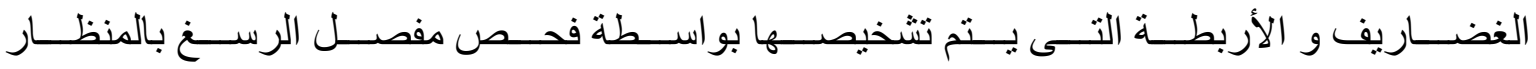

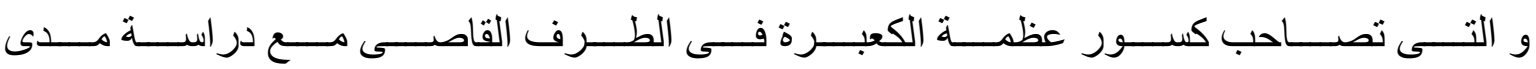
الإرتباطاً بين أنو اع الكسور المختلفة وهذه الإصابات المصاحبة.

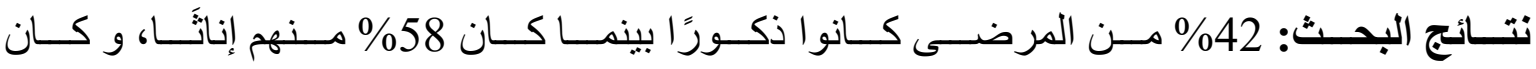

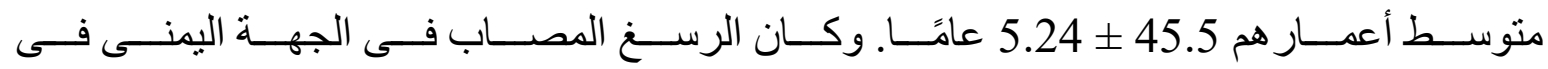

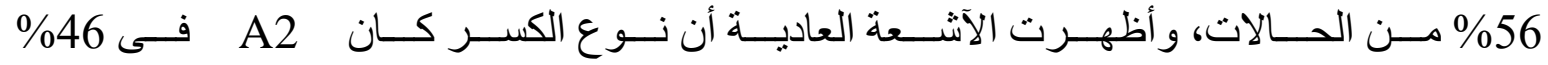

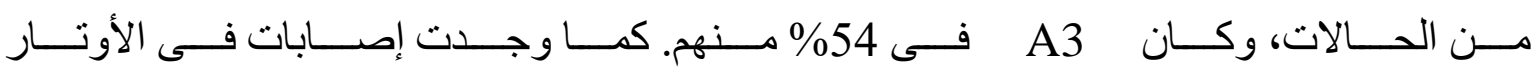

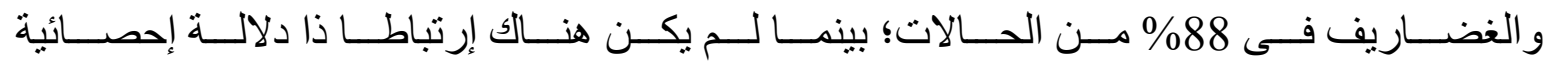
بين هذه الإصابات وتصنيف الكسور.

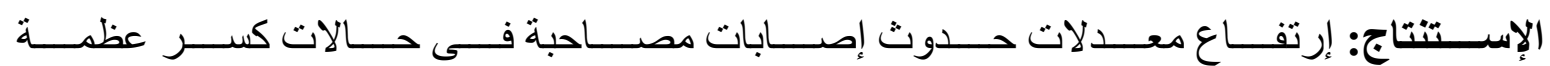

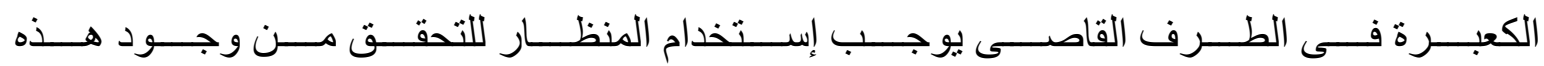

